\title{
TRIBUS URBANAS: DISCRIMINACIÓN Y COMUNIÓN EN LA ERA POSTMODERNA ${ }^{1}$
}

\author{
Luis Andrés Bahamondes González \\ Centro de Estudios Judaicos \\ Facultad de Filosofía y Humanidades \\ Universidad de Chile \\ lbahamondes7@hotmail.com
}

\section{RESUMEN:}

El impacto del fenómeno globalizador no solo es posible reconocerlo en sus aristas económicas o geopolíticas, es su influencia en los grados de asociatividad una de las aristas más relevantes en el plano social: agrupaciones juveniles convertidas en tribus urbanas, sectas, grupos asistémicos, etc., todo ello bajo el paradigma postmoderno de la pérdida de certeza absoluta. Frente a la incertidumbre y soledad, ya no solo se responde con individualismo, sino también, con colectivismo espontáneo.

PALABRAS CLAVE:

Tribus urbanas - Colectivismo - Incertidumbre - Postmodernidad

\section{ABSTRACT}

The impact of the globalizing phenomenon is not only recognizable on its economical and geopolitical aspects, being its influence on association degrees one of its main features regarding the social level: groups of young people turned into urban tribes, sects, antisystemic groups, etc., all of them under the postmodern paradigm of complete loss of certainty. Facing uncertainty and solitude, individualism ceased to be the only response. Spontaneous collectivism has become a new way of reaction.

\section{KEYWORDS:}

Urban tribes - Collectivism - Uncertainty - Postmodernity

\footnotetext{
${ }^{1}$ Publicado en Cuadernos Judaicos Nº26 (2009)
} 


\section{Introducción}

Hoy en día, en la era de la información - como afirmara Castells ${ }^{21}$, estamos asistiendo a la mediatización de las relaciones sociales. En este sentido, las tribus urbanas han logrado una cobertura importante en los medios de comunicación -periódicos, programas de radio y televisión, foros en internet- y consecuentemente en las conversaciones diarias. Algunas de línea más "tradicional" como los punkies, hardcores, skinheads y otras emergentes como los pokemones, emos, góticos, otakus, pelolais, etc. se han convertido en tema obligado.

Ante tal escenario, resulta interesante plantear de manera introductoria las siguientes interrogantes. La proliferación de tribus urbanas dentro de la sociedad chilena ¿constituyen instancias de comunión y asociatividad o, por el contrario, promueven la discriminación y xenofobia entre las diversas agrupaciones? ¿Es un síntoma más en la búsqueda de identidad dentro de la era postmoderna o simplemente una moda pasajera?

El presente artículo pretende diagnosticar y analizar el fenómeno de las "tribus urbanas" en el Chile actual, motivadas, en muchos casos, por la vorágine globalizadora de los cambios constantes, nuevas tecnologías y modas que irrumpen y pretenden otorgar cualidades y características prototípicas de identidad.

\section{Modelando identidades en la era postmoderna.}

Si entendemos la postmodernidad como la pérdida de la certeza absoluta, podremos comprender que el escenario en el que se desenvuelven las agrupaciones juveniles hoy en día obedece a la lógica de la incertidumbre, de la libertad plena, de la insatisfacción y del hedonismo. El escenario social ha cambiado y las formas de socialización siguen aquella dirección.

El proyecto modernizador en crisis, ha traído consigo nuevas formas de asociatividad al amparo de la postmodernidad, y el camino en la búsqueda de identidad recién comienza,

\footnotetext{
${ }^{2}$ Castells, 2004
} 
"las brújulas de antaño ya no sirven porque es todo el territorio el que ha cambiado drásticamente. Surge, entonces, la necesidad de reconstrucción social de un orden significativo en el cual reconocerse y en torno al cual orientar la vida",

De acuerdo a Larraín 2000, la declinación de las identidades tanto de clase como de nación, han dado paso a la proliferación de nuevas formas de asociativismo, cuyo objetivo principal radica en la lucha por el reconocimiento de su diferencia. Agrupaciones feministas, étnicas, ecológicas, sexuales, juveniles, etc. se enmarcarían en el contexto antes descrito.

Resulta complejo poder aunar dentro de la categoría "tribus urbanas" las diversas agrupaciones juveniles que se han desarrollado en el último tiempo, no obstante, podemos afirmar que existe una representación social de ellas. Teóricamente, toda representación es una construcción social, la cual se construiría a partir de dos elementos centrales: lenguaje y comunicación.

El análisis de fenómenos sociales desde este punto de vista nos otorga la posibilidad de describir los diversos tipos de cultura como tipos de lenguaje particulares, "que pueden quedar reflejados en historias verdaderas" ${ }^{4}$. Siguiendo el planteamiento de Habermas, podemos establecer que los códigos culturales - motivados por el lenguaje- son parte de un sistema de modelización, el cual construye un modelo del mundo y a la vez, un modelo de sí mismo.

La acción comunicativa - de acuerdo al planteamiento habermasiano-, se caracteriza por la interacción de, a lo menos, dos sujetos capaces de lenguaje y acción tendientes a entablar una relación interpersonal, por lo cual, la concepción de identidad se enlaza fuertemente con la de acción comunicativa señalada precedentemente, puesto que cada interpretación como acción de lenguaje requiere de entendimiento, vale decir, de una coordinación de

\footnotetext{
${ }^{3}$ Parker, 2000, p.88.

${ }^{4}$ Habermas, 1989, p. 193
} 
planes de acción. En este sentido,

“... la identidad se nos revela sólo como algo que hay que inventar en lugar de descubrir, como el blanco de un esfuerzo, "un objetivo”, como algo que hay que construir desde cero o elegir de ofertas de alternativas y luego luchar por ellas para protegerlas después con una lucha aún más encarnizada..."

Berger y Luckman, en su ya clásico libro La construcción social de la realidad nos planteaban la idea de interacción cara a cara, la cual ha sido sobrepasada en la actualidad por nuevas formas de comunicación motivadas por la tecnología. Las "tribus urbanas" en estudio, siguen manteniendo las formas tradicionales de comunicación cara a cara reuniéndose en diversos sectores de la ciudad ${ }^{6}$,;no obstante, resulta necesario visitar y vivir el denominado ciberespacio. Chats, fotologs, blogs, mensajes de texto, constituyen un elemento común al momento de caracterizar nuestros grupos de estudio. La existencia como miembro de una agrupación, se gana "viviendo internet". Fiestas, golpizas, "tocatas", reuniones, etc. se publicitan en sus páginas generando espacios informativos y dialógicos.

La conceptualización del fenómeno denominado "tribus urbanas", es de gran amplitud. Ello, provoca discordancia de opiniones al momento de considerar tal o cual agrupación perteneciente a dicha categoría. Costa, Pérez Tornero y Tropea, entienden las "tribus urbanas" como "las pandillas, bandas o simplemente agrupaciones de jóvenes y adolescente s que se visten de modo parecido y llamativo, siguen hábitos comunes y se hacen visibles, sobre todo en las grandes ciudades",7.

Es probable que la amplitud de la definición antes expuesta provoque cierto malestar al momento de comparar o incorporar diversas agrupaciones juveniles en la categoría "tribus urbanas".

\footnotetext{
${ }^{5}$ Bauman, 2005, p. 40.

${ }^{6}$ Parques, plazas públicas, campus universitarios, centros comerciales, entre otros.

${ }^{7}$ Costa, Perez Tornero, Tropea, 2005, p. 11.
} 
¿Cómo es posible comparar agrupaciones con bases ideológicas - con un relativo sustento teórico-con aquellas que aparentemente solo se basan en aspectos estéticos?

La respuesta no es sencilla, claramente agrupaciones juveniles como los punks, hippies, okupas, neonazis, entre otros, sustentaban su discurso y actos como respuesta transgresora frente a determinadas situaciones políticas, sociales y económicas (guerras, cesantía, conservadurismo, etc.), mostrándose como cartas opositoras a la cultura dominante, presentando alternativas y formas de respuestas no convencionales. A raíz de esto, se les reconoció como subculturas juveniles o contraculturas.

Si bien estos últimos hoy se encuentran presentes e $\mathrm{n}$ el escenario urbano nacional, la aparición de otras agrupaciones juveniles (conformadas por hombres y mujeres entre 14 y 24 años aproximadamente) ha provocado incomodidad al momento de las definiciones. En la actualidad, lo visual supera a lo auditivo, lo estético a lo discursivo. La postmodernidad trajo consigo la instantaneidad; la imagen adquiere velocidades que la oratoria no es capaz de alcanzar. En este contexto, recorren las urbes y el ciberespacio las denominadas "nuevas tribus urbanas", muchas de ellas surgidas desde los años 60, que han mutado en el siglo XXI, y otras que se han creado bajo la luz de este nuevo escenario socio-cultural. Frente a la conceptualización tradicional de las tribus urbanas Maffesoli postula que estamos frente a un neotribalismo, el cual

“... bajo sus distintas formas, se niega a reconocerse en cualquier tipo de proyecto político, no se inscribe dentro de ninguna finalidad y tiene como única razón de ser la preocupación por un presente vivido colectivamente" 8 . De esta manera, "el neotribalismo se caracteriza por la fluidez, las convocatorias puntuales y la dispersión. Solo así se puede describir el espectáculo callejero de las megalópolis modernas. El adepto al jogging, el punk, el que tiene un look retro, el típico "niño pijo”, los saltimbanquis callejeros, todos ellos nos invitan a un incesante travelling",9.

\footnotetext{
${ }^{8}$ Maffesoli, 1990, p. 138.

${ }^{9}$ Maffesoli, 1990, p. 140.
} 


\section{Des-integración sociocultural.}

La denominada "Generación X" y la posterior "Generación Y", han quedado atrás. La primera de mediados de los años 60 a los 80 , y la segunda de los 80 hasta el fin del milenio, estaban marcadas por una constante crítica a los modelos políticos, económicos y por el proceso de transición tecnológica. Los jóvenes del siglo XXI - de acuerdo a Carles Feixason parte de la "Generación @”. La cual se caracteriza por

"... expresar tres tendencias de cambio... en primer lugar , el acceso universal -aunque no necesariamente general- a las nuevas tecnologías de la información de la comunicación; en segundo lugar, la erosión de las fronteras tradicionales entre los sexos y los géneros; y en tercer lugar, el proceso de globalización cultural que conlleva necesariamente nuevas formas de exclusión social a escala planetaria" ${ }^{10}$.

No obstante el fuerte impacto del fenómeno globalizador- al que se refiere Feixa- , es importante considerar que si bien las culturas juveniles -en muchos casos- se inspiran o toman como referente agrupaciones o movimientos provenientes del extranjero, no dejan de incorporar elementos locales (como por ejemplo la jerga), lo cual trae como consecuencia, factores de arraigo, pertenencia e identidad en la agrupación, es decir, me siento parte de algo que reconozco.

Siguiendo la línea argumentativa de Palm, "las culturas juveniles son siempre locales, sin ningún género de dudas, a pesar de los detalles derivados globalmente" ${ }^{11}$. De esta manera, en la instauración conceptual del "adolescente global", la globalización actuaría no como un padre que concibe a este hijo, sino como un padre sustituto proveedor de insumos que influyen en éste, cuyos hijos reconocen a su padre y reaccionan frente a él, sin olvidar que sus raíces se encuentran en el ámbito local.

\footnotetext{
10 Feixa, 2006, pp. 58-59.

11 Pam, 2004. p. 42.
} 
"Que los medios de comunicación de masas y comercialización transnacional hayan contribuido con entusiasmo a la imagen de un "adolescente global" que lleva ropa vaquera, zapatillas deportivas y mochila, y que probablemente ve la MTV y bebe Coca Cola, no quiere decir que se trate de un concepto que se pueda defender, puesto que son semejanzas relativamente superficiales. No implican la condición de miembro de una cultura común" ${ }^{\prime 2}$.

La diversidad es un elemento central de análisis, puesto que ésta implica diferenciación. Esta diferenciación trae consigo en muchos casos, elementos de discriminación y xenofobia. Es en este contexto donde aparece

"la idea de la defensa de los valores (propios del grupo), y un territorio exclusivo, que le pertenece a éste (barrios exclusivos, un bar determinado, una esquina cualquiera, un estadio). Y finalmente, el establecimiento de recorridos activos por la ciudad y sus suburbios, en busca de amigos o enemigos a quienes saludar o atacar" ${ }^{\text {"13 }}$.

Han sido denominados de diferentes maneras: Skinheads, punks, hardcores, catalogados como "sectas destructivas", "grupos violentistas", "agrupaciones antisistema". Raperos y flaites, como delincuentes y drogadictos. Emos, góticos, otakus, como homosexuales. La connotación negativa está presente.

Las denominadas "barridas" skinheads, son un ejemplo prototípico. Son consideradas por sus miembros como parte del sistema de persecución y "limpieza" de determinadas agrupaciones de la ciudad, entre ellos, punks, raperos, emos, etc.

Otros, destacan las agrupaciones antes señaladas como instancias y espacios de sociabilidad en un mundo donde la tónica es el individualismo.

La simultaneidad en su actuar, caracteriza el funcionamiento de las "tribus urbanas". Por

12 Ibidem.

13 Silva, 2002, p. 124. 
una parte, resultan elementos de atracción el fortalecimiento del compañerismo, la lealtad y el afecto al interior de la agrupación (intragrupal), con actos ligados a la discriminación, xenofobia y violencia hacia el entorno (extragrupal).

"Un skin, por ejemplo, buscará combatir a los que considera guarros mendigos, homosexuales, gentes de otras razas, punks- alardeando de su capacidad de violencia... pero al mismo tiempo, alentará y mimará cariñosamente a los miembros recién llegados a su grupo",14

La "oferta tribal" en un mundo postmoderno debe ser amplia. En algunas de ellas existe un predominio ideológico, estético y musical, entre otras características. Solo describiremos algunas de ellas de modo ilustrativo.

Los veganos, se caracterizan por ser "vegetarianos extremos o puros", no consumen productos de origen animal y visten de manera tradicional. Su identificación en las calles resulta prácticamente imposible. La visibilidad de este grupo, está dada por sus constantes protestas frente a instituciones que atentan contra sus ideales. Sus blancos preferidos son empresas de comida rápida, centros de experimentación animal, empresas y tiendas que utilizan insumos animales, etc.

Los otakus, constituyen una agrupación de fácil identificación. Su origen está en Japón, y logra alcances a nivel nacional, a partir de los dibujos animados llamados "animé". Tomando su estética, música e idioma se han transformado en seguidores de la cultura japonesa. El principal proveedor de información es internet, gracias a la cual muchos de los integrantes de esta tribu urbana han adoptado nombres japoneses y participan en foros de discusión tanto en Chile como en el extranjero.

Es probable que tanto pokemones como pelolais constituyan las agrupaciones juveniles con mayor cobertura mediática. Los primeros (hombres y mujeres), en su mayoría, provenientes de sectores medios y bajos, visten en general buzo y zapatillas y son de fácil reconocimiento a través de sus cortes de de pelo y peinados (alisado artificialmente, cortes

\footnotetext{
${ }^{14}$ Costa, Perez Tornero, Tropea, 2005, p.14.
} 
de pelo irregulares, teñido multicolor, etc.). Dentro de su música preferida está el reggaeton, lo cual influencia la estética a seguir (cadenas, pulseras, aros, etc.)

La terminología pelolais, identifica aquellas jóvenes de estratos sociales acomodados (anteriormente denominadas “cuicas”). Su identificación está ligada a su condición social y la denominación hace referencia a jóvenes de pelo liso, preferentemente rubio, que visten ropa de marcas caras y asisten a colegios particulares.

Las diferentes agrupaciones juveniles buscan libertad, asociación, identificación con sus pares, con sus iguales, con los cuales compartir miedos y disfrutar libertades. Es una constante búsqueda, que otorga flexibilidad a la agrupación. La moda ayuda a la masificación. Me distingo de los que no son iguales a mí por mi vestimenta, lenguaje, tatuajes, piercing, color de pelo, música, etc., en síntesis, "las culturas juveniles se traducen en estilos más o menos visibles, que integran elementos materiales e inmateriales heterogéneos..." 15.

La flexibilidad es la clave. Un día es posible ser gótico y al otro día ser punk, no hay reproche, no hay imposición, hay que buscar nuevas experiencias; estamos frente a un juego de “des-integración” permanente. Siguiendo el planteamiento de Lipovetsky "la última moda es la diferencia, la fantasía, el relajamiento; lo estándar, la rigidez, ya no tiene buena prensa. El culto a la espontaneidad y la cultura psi estimula a ser más uno mismo, a analizarse, a liberarse de roles y complejos ",16.

\section{La cultura del ocio: donde todo es compartido y comprendido.}

En nuestra sociedad extremadamente normada, la identificación con determinada "tribu urbana" supone liberación. No obstante, la dinámica esquizofrénica de nuestra sociedad actual, nos plantea ciertas paradojas; necesitamos una "libertad protegida". Ya no hay

15 Costa, Perez Tornero, Tropea, 2005, p.109.

16 Lipovetsky, 2002, pp. 21-22. 
abandono del hogar en los componentes de estas tribus, en su mayoría no está presente la irrupción de un líder carismático que determine el qué hacer. Con excepciones, eso parece ser cosa del pasado. Seguimos inmersos, al menos de manera formal, bajo el amparo paterno y educativo.

Las diversas agrupaciones juveniles, posibles de agrupar bajo el canon de "tribus urbanas", se presentan como espacios de socialización libertaria donde se comparten experiencias, se buscan soluciones a determinadas problemáticas o sencillamente se escapa de ellas. El consumo de drogas y alcohol es parte de la socialización, al igual que el sexo. Todo es compartido y comprendido.

Han creado espacios físico-virtuales en medio de la ciudad, para el goce del ocio. Es un mundo donde las decisiones son pendulares. A veces necesito protección, pero al instante quiero libertad, exijo atención de mi entorno, pero la soledad es una buena compañía, busco diversión, pero amo la tranquilidad. Es un constate qué quiero hacer, decir, probar, etc. Sin embargo, “añoramos una guía confiable para liberarnos al menos de parte del espectro de responsabilidades de nuestras elecciones" $" 17$.

\section{Comentario final.}

Las "tribus urbanas" que han logrado notoriedad pública en el último tiempo en nuestro país, de acuerdo a nuestro planteamiento, se enmarcan en el desarrollo de nuevos tipos de socialización cuyo sustento a simple vista parece estar más en la forma que en el fondo. Si bien la mediatización a la que han sido expuestas las agrupaciones juveniles ha ayudado a su masificación como objeto de estudio, los métodos y técnicas de análisis de éstas siguen siendo difusos.

La sociedad chilena, conservadora en su generalidad, por una parte avala la conformación de estas agrupaciones juveniles, en la medida que éstas son una moda y que prontamente dejaran esta actitud pasajera y, por otra parte, se mantiene expectante frente a las opciones

17 Bauman, 2004, p.28. 
que ellas puedan generar en la juventud. El futuro de Chile debe ser conservador, no debe ser ambiguo sexualmente, no debe ser drogadicto ni alcohólico. En definitiva, no debe cometer excesos.

¿Cómo responden las agrupaciones juveniles frente a dichas imágenes de la sociedad adulta? Al parecer con tolerancia, la que, como plantea Bauman, solo puede expresarse como indiferencia ${ }^{18}$, peligrosa apatía.

Ya no hay construcción de estilos de vida. "En nuestros días se ha deslegitimado la idea de autosacrificio; la gente ya no se siente perseguida ni está dispuesta a hacer un esfuerzo por alcanzar ideales morales ni defender valores morales; los políticos han acabado con las utopías y los idealistas de ayer se han convertido en pragmáticos "19

Estamos acostumbrados a la institución, a un extraño orden "a la chilena"; a la jerarquización con la cual funcionan movimientos sociales, pandillas y bandas en las grandes urbes. Esta nueva forma de socialización (tribus urbanas, neo-tribus) no tiene nada de aquello ni lo pretende; se establecieron en la ciudad como agrupaciones juveniles de funcionamiento horizontal. Pokemones, pelolais, emos, otakus, veganos, flaites, visual, etc., no poseen líderes que, cual mesías, les indiquen el camino a seguir... ¿cuál camino?

Nos encontramos inmersos en mega-sociedades donde las fronteras físicas ya han sido traspasadas. La instauración de agrupaciones de todo orden (juveniles, étnicas, ecológicas, etc.) actúa como una forma de respuesta defensiva frente al intento avasallador de homogeneización global. Se me exige cada vez más definirme políticamente, sexualmente, educacionalmente, religiosamente, ante lo cual necesito defenderme; cuál enemigo acecha mi territorio, necesito protección (entendida en muchos casos como evasión).

Es, tal vez, en el ámbito de la afectividad donde las agrupaciones juveniles antes señaladas

\footnotetext{
18 Bauman, 2004, p. 9.

19 Bauman, 2004, pp. 8-9.
} 
motiven líneas de estudio y análisis relevantes al momento de rescatar el sentido de arraigo y pertenencia que generan al interior de sus redes sociales. De acuerdo a Ganter y Zarzuri,

"los afectos son los que construyen vínculos moleculares en estas nuevas agrupaciones, vínculos que se transforman en lealtades, en ayudas, en construcciones de identidades asociadas a expresiones particulares $o$ geográficas específicas. De esta forma, los afectos posibilitan hablar... de una nueva trama familiar: e l grupo, la música, la imagen, el graffiti, se van reconstituyendo como... nuevas formas de habitar ese "otro" hogar, de coexistir en el mundo" 20.

\section{Anexo}

20 Gunter y Zarzuri. 1999, p.16. 


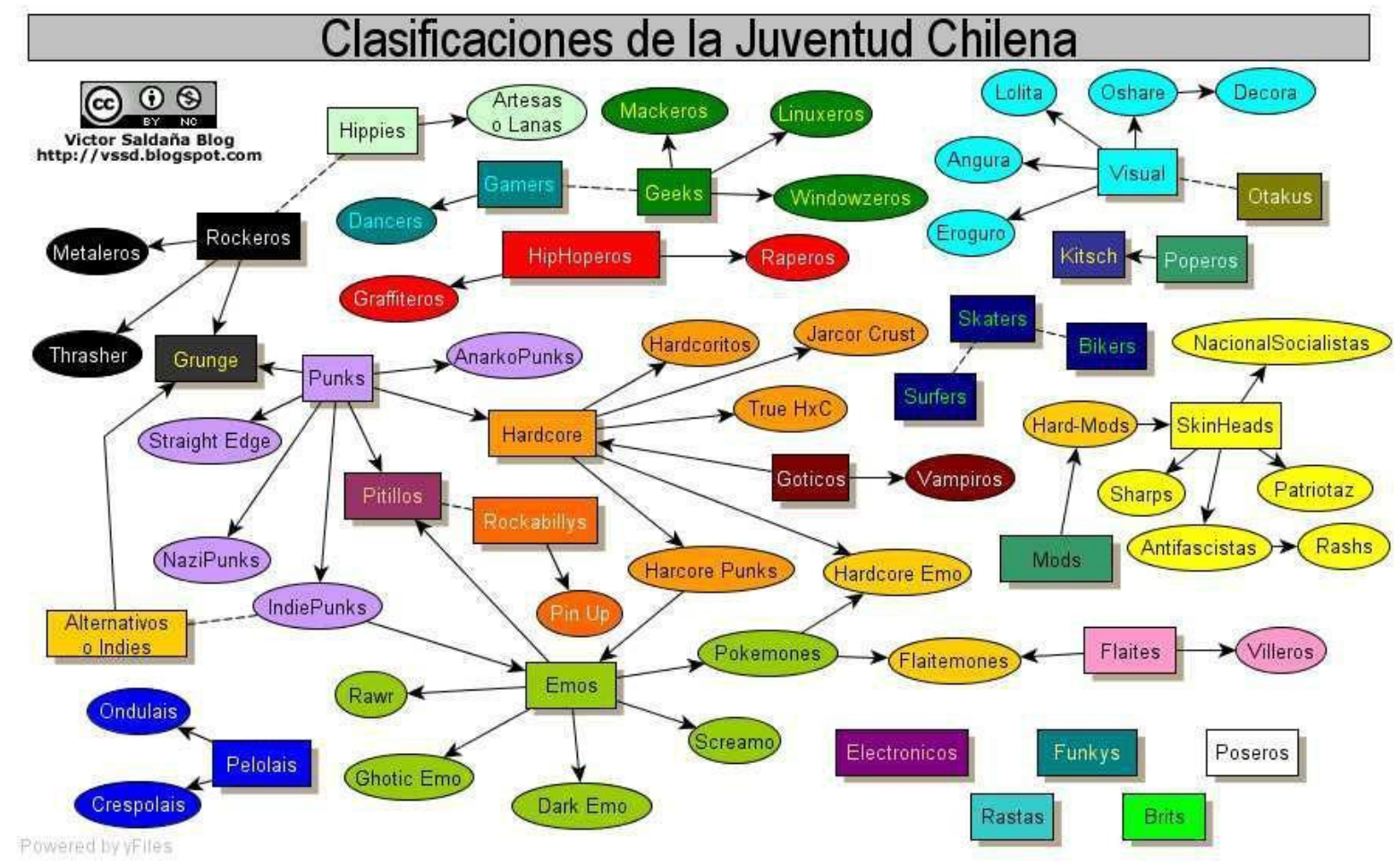

\section{REFERENCIAS BIBLIOGRÁFICAS.}

BAUMAN, Z. Ética Posmoderna. . Buenos Aires, Ed. Siglo XX1, 2004.

BAUMAN, Z. Identidad. Buenos Aires, Ed. Losada, 2005.

BERGER, P. y LUCKMANN T., La construcción social de la realidad. Buenos Aires, Ed. Amorrortu, 1993.

CASTELLS, M. La era de la información: economía, sociedad y cultura. Madrid, Siglo XXI, 2004.

CASTILLO, H. "De las bandas a las tribus urbanas. De la trasgresión a la nueva identidad social".

Revista Desacatos, nº 9, CIESAS, México: 57-71, 2002. 
COSTA, P., PEREZ TORNERO, J. M., TROPEA, F. Tribus urbanas. Barcelona, Ed. Paidós, 2005.

FEIXA, C. De jóvenes, bandas y tribus. Barcelona, Ed. Ariel, 2006.

GUNTER, R. y R. ZARZURI. "Tribus Urbanas: por el devenir cultural de nuevas sociabilidades juveniles". Revista Perspectivas: notas sobre intervención y acción social, $\mathrm{n}^{\circ}$ 8. Universidad Católica Cardenal Raúl Silva Henríquez. Santiago de Chile: 5-19.Diciembre 1999.

HABERMAS, J. Teoría de la Acción Comunicativa. Vol. II. México, Ed. Taurus, 1989.

LARRAIN, J. Modernidad, razón e identidad en América Latina. Santiago de Chile, Ed. Andrés Bello, 2000.

LIPOVETSKY, G. La era del vacío. Barcelona, Ed. Anagrama, 2002.

MAFFESOLI, M. El tiempo de las tribus: el declive del individualismo en las sociedades de masas. Barcelona, ICARIA, 1990.

PAM, N. “Culturas Juveniles Globales". Revista de Estudios de Juventud: De las tribus urbanas a $\underline{\text { las }}$

culturas juveniles, nº 64. Instituto de la Juventud (INJUVE). Madrid: 39-47, marzo 2004.

PARKER, C. Los jóvenes chilenos: cambios culturales; perspectivas para el siglo XXI. Santiago de Chile. Unidad de Estudios Prospectivos, MIDEPLAN - Instituto de Estudios Avanzados, Universidad de Santiago. 2000. 
REGUILLO, R. "La performatividad de las culturas juveniles". Revista de Estudios de Juventud: De las tribus urbanas a las culturas juveniles, $n^{\circ}$ 64. Instituto de la Juventud (INJUVE). Madrid: 4956, marzo 2004.

SILVA, J. "Juventud y tribus urbanas: en busca de la identidad". Revista Última Década, n 17. Centro de Investigación y Difusión Poblacional de Achupallas (CIDPA). Viña del Mar: 117-130, 2002. 